\title{
Failure mechanics of joined rock mass
}

\author{
J. Vacek \& S. Sedláčková \\ Czech Technical University at Prague, Klokner Institute, Czech Republic
}

\begin{abstract}
Failure of rock mass is not a static process, but has its own history. Its duration varies from several seconds to several hundreds years. Rock mass movements are often hundreds of metres and significantly change its original shape. Failure mechanics can be studied experimentally. On nonhomogeneous models we can observe the onset of failure (prior to and during the failure deformations increase on sliding surfaces), the chronology of various stages of failure (cave-ins, slides), and the final shape of rock mass. We can also observe influences, exerted by modelled joints, adits and other features, upon the failure history and shapes of cave-ins and slides.

Methods used for the study of geotechnical problems are based on two presumptions:
\end{abstract}

- results must be time dependent

- results must allow the creation of joints in the rock mass before the study event and during the event must allow movement of rock along the joints, opening of the joints and creation of new joints. The direction of modelled joints must be similar to reality, i.e. their direction and inclination must be the same as in real-life. These measures make it possible to create the structure of modelled rock mass similar to real ones. The filling of cracks must be equivalent to real ones.

As a basic method of study of the geotechnical problems of caving and rock pillar with adit and joints, scale physical models were used from equivalent materials. Slips and bumps were also studied mathematically.

The solution must allow an extrusion of rock into an open space (for bump study only).

Keywords: mining, rock mechanics, mathematics and physical modelling, joints, rock pillar, cave-in, rock burst, bump. 


\section{Caving of underground open space}

Figs. 1-4 show the caving of an excavated open space in the Měděnec Mine.

The worked-out space is situated in magnetite; in the actual hanging wall there are skarns and further on gneisses. The deposit depth is $200 \mathrm{~m}$ under the surface, and its width in the area studied is $90 \mathrm{~m}$, with a height of $60 \mathrm{~m}$. It is crossed by a prominent fault. Its thickness is $6 \mathrm{~m}$ and it is filled with migmatites, tectonic clay, etc. In the homogeneous model of this geological mining situation the failure occurred suddenly, the roof of the room, after falling into the workedout space, had the shape of a parabola, and the caving did not reach the surface. Figs. 1-4 show the caving of a structural model. The situation prior to the caving is shown in Fig. 1, the first stage of the caving is in Fig. 2, the second in Fig. 3 (it began one minute after the first stage of the caving), and the final stage of the caving (which began 10 minutes after the first caving) is shown in Fig. 4. Before the first caving and during full time of event, creaking could be heard from the model. In the real case of the Měděnec Mine, subsidence of the surface did occur. It has a conical shape, with a depth of $35 \mathrm{~m}$ and a diameter of over $100 \mathrm{~m}$.

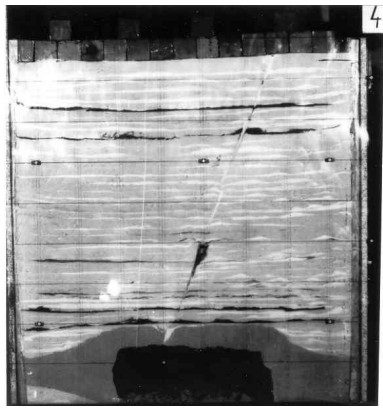

Figure 1: State before failure.

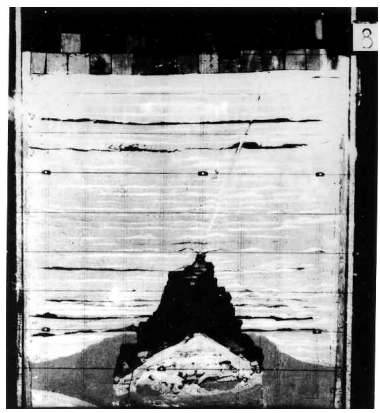

Figure 3: Second stage of failure one minute later.

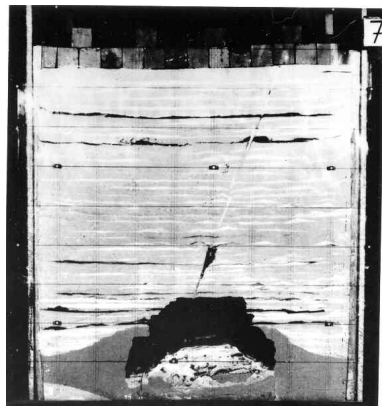

Figure 2: First stage of failure.

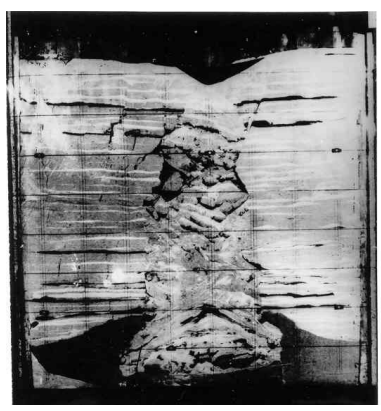

Figure 4: Final stage of failure, ten minutes later. Surface cavein appears. 


\section{Rock mass pillar with joints and adit}

The figures 7-9 show the failure history of a pillar with an adit in its centre and three joints with $30^{\circ}$ inclination (Fig. 5). The dimensions of the pillar in reality are height $50 \mathrm{~m}$, width $10 \mathrm{~m}$ and length $60 \mathrm{~m}$. The width of the adit is $2.4 \mathrm{~m}$. The rock mass is magnesite. Joints with sand filling were made in the model.

Fig 6 shows the model before testing. Figs. 7-9 show successive stages of the failure. The differences between the homogeneous (Fig 12) and inhomogeneous pillars are clearly visible. The failure of the homogeneous pillar was sudden, with one or two shear planes. The vertical deformation before the failure was around $1.5 \%$. The failure of the inhomogeneous pillar was more complex. It was not instantaneous (the duration of failure depends on the loading rate; in the model presented is was $390 \mathrm{sec}$ and the axial deformation is 3-10\% (in the model presented it is $8 \%)$ ). It follows that, in spite of a lower bearing capacity (54\% of bearing capacity of full and homogeneous one), the pillar with an adit was, from the point of view of mining, more advantageous. The model displays an extremely complicated failure. Usually the failure is simpler (Fig. 11), but it is never so simple as in a homogeneous model. If adit is on the centre of pillar, failure usually starts with vertical crack, which begins on the adit. If the homogeneous model has a bearing capacity around $20 \mathrm{kN}$, it is hardly believable that the model, at the stage shown in Fig. 8 , can still bear $5 \mathrm{kN}$, and $1.5 \mathrm{kN}$ at the stage in Fig. 9. The load-deformation curves of Pillars 4.1 (Figs. 5-9), E7 (Fig. 12) and E10 (Fig. 11) are shown in Fig. 13.

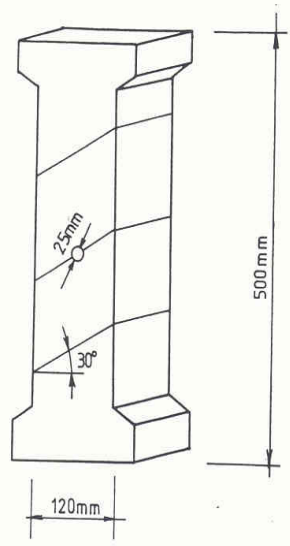

Figure 5: Schema of studied pillar.

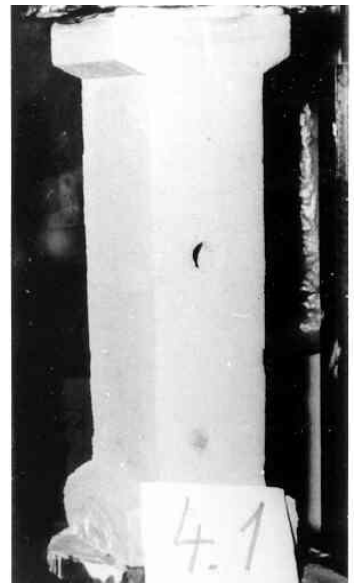

Figure 6: Pillar 4.1 before test.

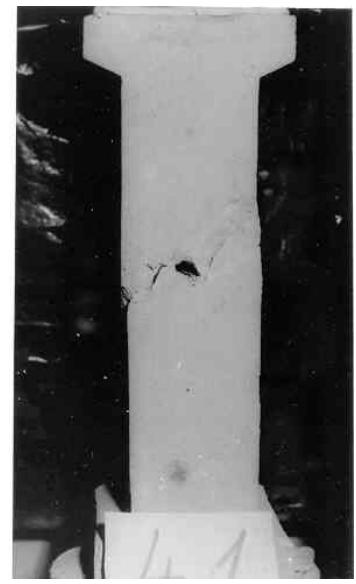

Figure 7: Pillar 4.1. The first stage of failure. 


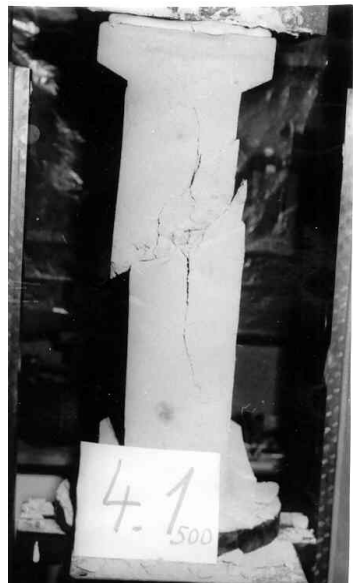

Figure 8: Failure continues.

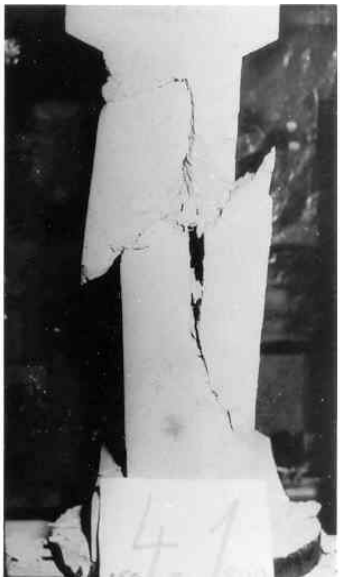

Figure 9: Stage of failure before total collapse.

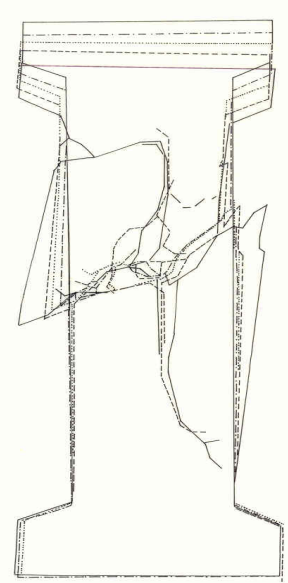

Figure 10: Change of shape of pillar 4.1 during failure.

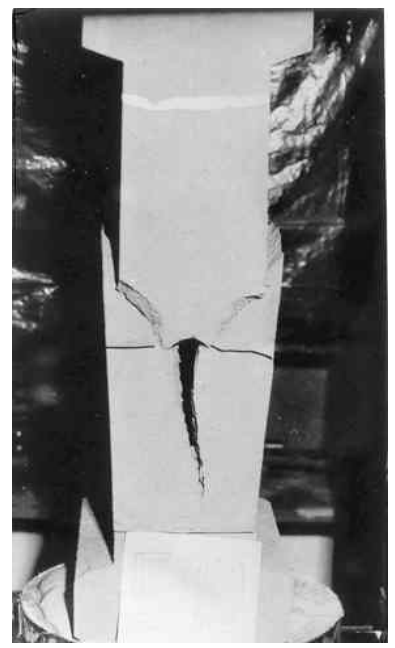

Figure 11: Failure of pillar E10 with horizontal joints.

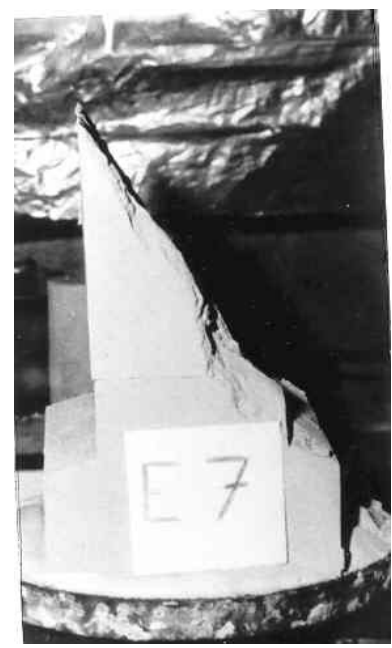

Figure 12: Typical failure of homogeneous pillar (E 7).

\section{Study of bumps}

Bumps are the most dangerous event that can occur during excavation work and happen in underground open spaces, caused by severe forces in the surrounding rock. This can injure or kill mining workers and destroys excavation spaces. Therefore, the study of this problem is very important for theory and practice. 


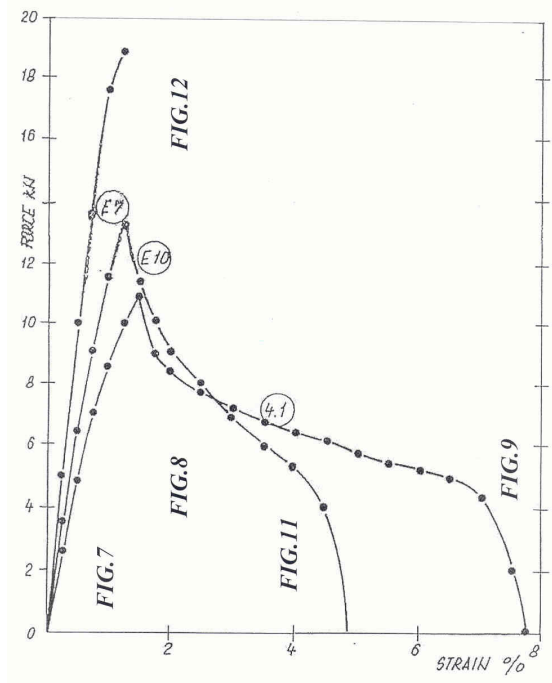

Figure 13: Deformation curves of pillars 4.1, E 10 and E7.

For bump occurrence it is necessary to have sufficient high pressure in the bump location (usually at great depth, but also through tectonic pressure) and the rock must be brittle and must have a disposition for a bump (properties that allow creation of bumps).

The occurrence of bumps is also dependent on the speed of mining. In the same conditions, when we excavate slowly, we give the rock mass sufficient time to create cracks in the open space vicinity. This means that stress concentrations around the excavation reduced, and bumps do not occur. If mining work proceeds rapidly, cracks do not have time to occur and bumps appear. Old mining experience confirms it. Also our experiments prove this fact. When the loading speed was increased by a factor of five the bumps were so strong that they partly destroyed our device. When the loading speed was reduced by a factor of five, bumps were very weak. This is also the reason why this event is studied as a time dependent problem (see [3, 5-8]).

Bump was studied for the case of a mine gallery inside a horizontal coal seam. Its mechanics and stress distribution on the top of the seam was studied by mathematical and experimental modelling.

\subsection{Testing devices}

\subsubsection{Loading cell}

The loading cell is shown on Fig.14. It consists of the lower steel tank, which is designed for the horizontal forces caused by vertical load in araldite specimens. The loading cell is equipped with lucites on its sides. It allows observation of samples during the tests. The tank is shown on Fig. 15. This loading cell models (simulates) the rock mass in the vicinity of the seam. In the loading cell we placed two araldite specimens (with dimensions of 160/400/40 mm), which 
model coal seam. The gap between them corresponds to the width of a working gallery in a mine. We observed the mechanism and the history of coal bumps. The araldite specimen was covered with a soft duralumin sheet, and a force meters were placed on it in the following manner: 5 comparatively thick force meters were placed near its outer edge and another 15 thinner force meters were placed next to them, (see Fig. 14 and Fig. 16). A 300mm high block of duralumin was placed over this sheet. This block simulates the handing wall. It modelled stress distribution similar to that in reality (see Fig. 15).

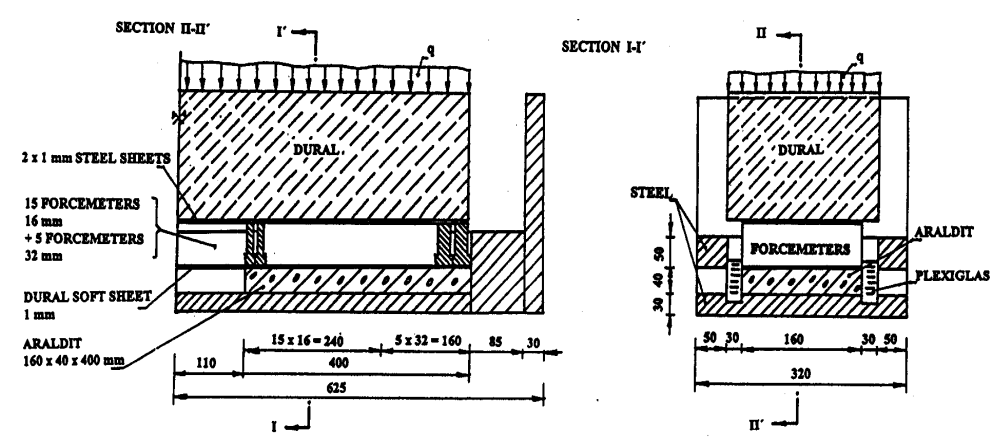

Figure 14: Scheme of loading cell.

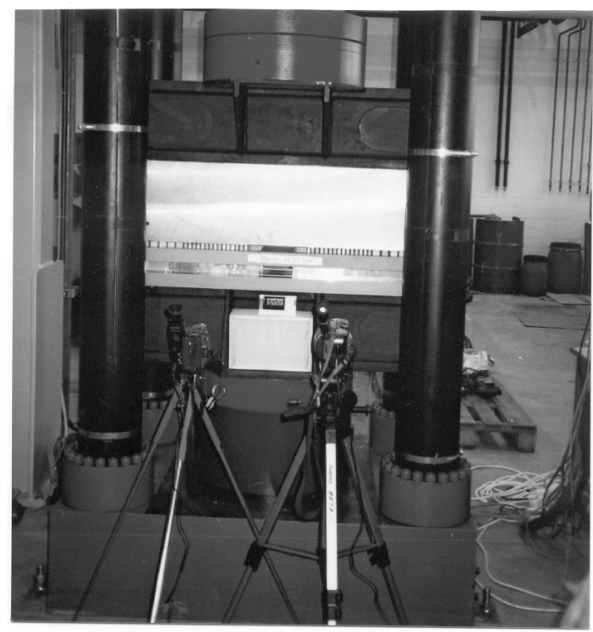

Figure 15: Testing device. Two camcorders recorded the test.

\subsubsection{Force meters}

Fig. 16 shows the force meters. The force meters are $160 \mathrm{~mm}$ in length, $68 \mathrm{~mm}$ in height, and 16 or $32 \mathrm{~mm}$ in width. There are 4 strain gauges on each force meter 2 on one side $30 \mathrm{~mm}$ from the edge of force meter and 2 on the other side $60 \mathrm{~mm}$ 
from the edge of the force meter. These allow us to measure the deformation along its full length. The strain gauges are connected in series in order to be able to gauge each force meter separately and at the same time to increase the gauging sensitivity. The force meters indicated by numbers $1,2 \ldots 30$ (width $16 \mathrm{~mm}$ ), 31, $32 \ldots 40$ (width $32 \mathrm{~mm}$ ) calibrated within the expected range of forces, i.e., 0 to $250(500) \mathrm{kN}$.

The readings of every force meter were automatically read by a Brüel \& Kjaer strain gauge bridge every 10 seconds and sent to a computer. Reading of all 40 force meters takes $1,2 \mathrm{~s}$.

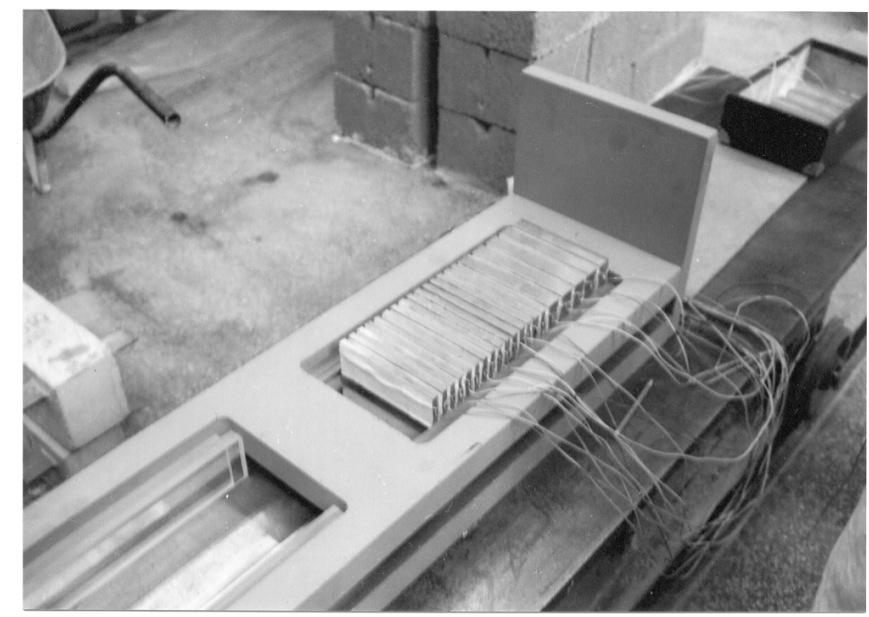

Figure 16: Loading cell. Right with sample and force meters.

\section{Mechanics of bumps}

The final experimental runs were also recorded with a high speed camera. It makes it possible to watch bumps as a several second events. From continuous records Figures 17-20 were chosen. Notice that the studied bump starts (similar to earthquake) with small extrusion of rock mass, Fig. 18, then follows the main part of bump, Fig. 19 and 20. Event sometimes finish with small rock extrusion, not in described case.

\section{Mathematical model}

$P F C^{2 D}$ (Particle Flow Code in Two Dimensions) developed by Itasca, USA was used for the numerical modeling part of the project. A physical problem concerning the movement and interaction of circular particles may be modelled directly by $P F C^{2 D} . P F C^{2 D}$ models the movement and interaction of circular particles by the distinct element method (DEM), as described in $[1,2,4]$. 
258 Monitoring, Simulation, Prevention and Remediation of Dense and Debris Flows

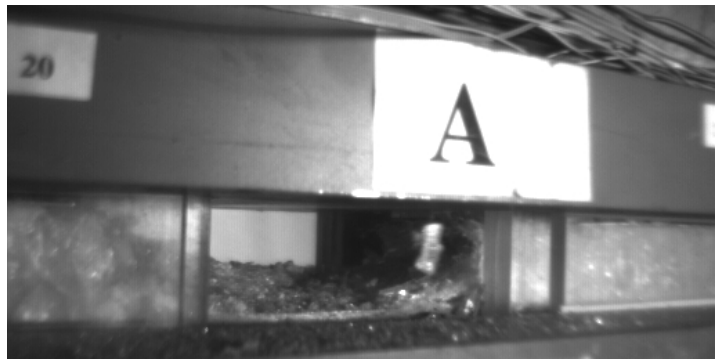

Figure 17: State before bump.

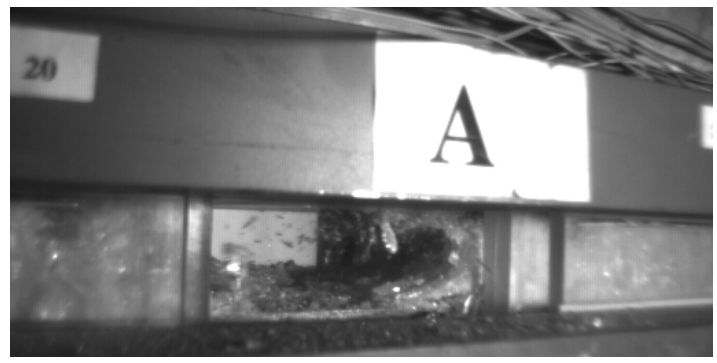

Figure 18: First extrudes appears.

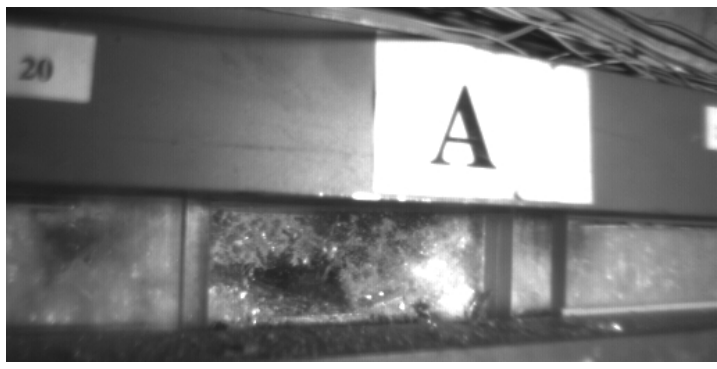

Figure 19: Early stage of bump.

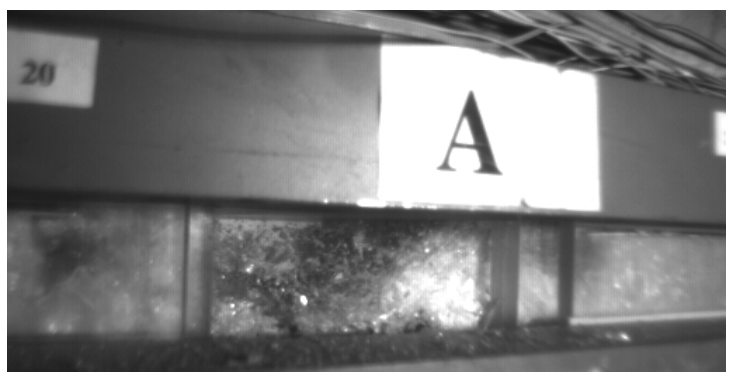

Figure 20: Late stage of bump. 
Bonding two or more particles together can create particle of arbitrary shape: these groups of particles act as autonomous objects, provided that their bond strength is high. As a limiting case, each particle may be bonded to its neighbor: the resulting assembly can be regarded as a "solid" that has elastic properties and is capable of "fracturing" when the bonds break in a progressive manner. $P F C^{2 D}$ contains extensive logic to facilitate the modeling of solids as close-packed assemblies of bonded particles; the solid may be homogeneous, or it may be divided into a number of discrete regions of blocks.

The calculation method is a time stepping, explicit scheme. Modeling with $P F C^{2 D}$ involves the execution of many thousands of time steps. At each step, Newton's second law (force $=$ mass $\mathrm{x}$ acceleration) is integrated twice for each particle to provide updated velocities and new positions, given a set of contact forces acting on the particle. Based on these new particle positions, contact forces are derived from the relative displacements for pairs of particles: a linear or non-linear force/displacement law at contacts may be used.

Fig. 21 shows details of the mathematical model after a bump with ball velocities. On the right-hand side the bump starts and extrusions are clearly visible. On the left-hand side the bump is fully developed. The described case was in a coal seam with modelled cracks at an angle of $60^{\circ}$ from the horizontal level. Bonds between balls on these joints were 10 times smaller. The stress grew until the bump initiation.

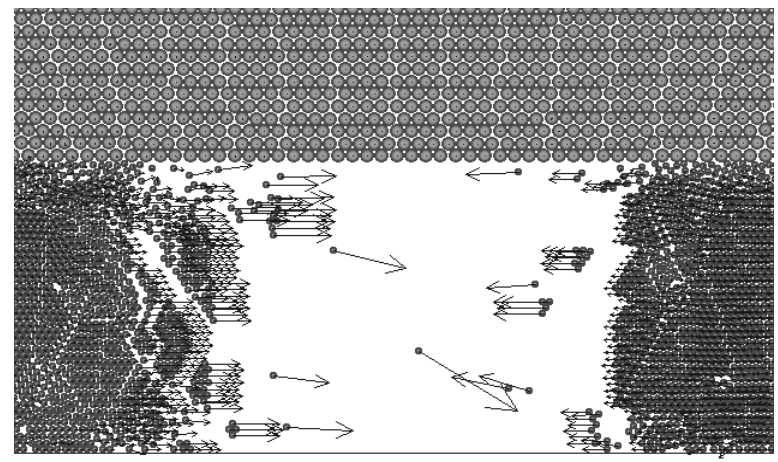

Figure 21: Bump on a coal seam.

\section{Conclusion}

A combination of experimental and mathematical models appears very appropriate for a study of the stress distribution in a coal seam before and after bump initiation. Both methods enable a time dependent study of the problem, and make it possible to study the development of cracks during bump initiation, and this extrusion of material into an open space during a bump. They thus offer a description of the problem that is very close to reality. 


\section{Acknowledgements}

This research and this paper have been sponsored by the Grant Agency of Czech Republic, (GAČR), grant number 103 / 05 / 0334 "Mechanics of brittle rock failure in critical depth"

\section{References}

[1] Cundall, P.A., O.D.L. Strack: The Development of Constitutive Laws for Soil Using the Distinct Element Method, Numerical Methods in Geomechanics, Vol. 1, pp.289/317. Rotterdam, A.A. Balkema, 1979.

[2] Cundall, P.A.: Distinct Element Models of Rock and Soil Structure, Analytical and Computational Methods in Engineering Rock Mechanics, Chapter 4, pp. 129/163. E.T. Brown, Ed. London 1987.

[3] Foss, M., M., Westman, E., C.: Seismic Method for in-seam coal mine ground control problems, SEG International Exposition and $64^{\text {th }}$ Annual Meeting, Los Angeles, 1994, p 547 - 549.

[4] Magnier, S.A., Donzé, F.V.: Numerical Simulation of Impacts Using a Discrete Element Method, Mech. Cohes.-Frict. Mater., 3, 1998, 257-276.

[5] Vacek, J., Procházka, P.: Rock bumps occurence during mining, Computation Methods and Experimental Measurements X, Alicante, 2001, p. $437-446$.

[6] Vacek J., Bouška, P.: Stress distribution in coal seam before and after bump initiation, Geotechnika 2000, Glivice- Ustroň 2000, p. 55- 66.

[7] Vacek, J., Procházka, P.: Behaviour of brittle rock in extreme depth, 25th Conference on Our World in Concrete \& Structures, Singapore, 2000, p. $653-660$.

[8] Vacek, J., Sedláčková, S.: Mathematical and experimental study of rock bump mechanics, CMEM 2005, Malta, 2005, p. 